\title{
DAMPAK RENDAHNYA HARGA KARET TERHADAP KONDISI SOSIAL EKONOMI PETANI KARET DI SUMATERA SELATAN
}

\author{
Low Rubber Prices Impact on Socio Economic Condition of Rubber Smallholders \\ in South Sumatera
}

Lina Fatayati SYARIFA ${ }^{1}$, Dwi Shinta AGUSTINA*, Cicilia $\mathrm{NANCY}^{1)}$, dan Muhammad SUPRIADI ${ }^{2)}$

${ }^{1)}$ Balai Penelitian Sembawa, Pusat Penelitian Karet

Jalan Raya Palembang - P. Balai KM 29, Palembang 30001 Sumatera Selatan

Email: dwishinta_sbw@yahoo.com

${ }^{2)}$ PT. Riset Perkebunan Nusantara

Jl. Salak No. 1A Bogor 16151 Jawa Barat

Diterima : 5 Agustus 2015 / Direvisi : 3 Februari 2016 / Disetujui : 1 April 2016

\begin{abstract}
The low rubber price has given some impacts on socio economic condition of smallholders in South Sumatera because more than $40 \%$ of South Sumatera population depends on rubber commodity. This paper describes the results of research on impact of low rubber price on socio economic conditions of smallholders in South Sumatera. The study was conducted in South Sumatera Province in 2014 by survey method. The sample of smallholders was selected by random sampling. Furthermore, this activity also selected rubber nursery operators, leasing companies and dealers of motorcycle, leasing company and store of electronics and furniture around the rubber center area in South Sumatera by purposive sampling. The results showed that low rubber prices had given impacts to the decrease of farmers' income per month, the decrease of investment by farmers, the decrease of farmers' purchasing power, as well as the changes of income source offarmers. Moreover, there had been changes of land use from rubber farming to other crops. Therefore, it was needed some efforts to be able to survive in low rubber prices conditions.
\end{abstract}

Keywords: Impact; low rubber price; socio economic; rubber smallholders

\footnotetext{
Abstrak

Rendahnya harga karet telah memberikan berbagai dampak terhadap
}

kondisi sosial ekonomi petani karet di Sumatera Selatan (Sumsel) dikarenakan lebih dari 40\% penduduk Sumatera Selatan menggantungkan hidupnya dari komoditas karet. Tulisan ini menguraikan hasil penelitian mengenai dampak turunnya harga karet terhadap kondisi sosial ekonomi petani karet di Sumatera Selatan. Kegiatan penelitian dilakukan di Provinsi Sumatera Selatan pada tahun 2014. Penelitian dilakukan dengan metode survei dengan mengambil sampel petani karet yang dipilih secara acak. Selanjutnya secara sengaja dipilih sampel penangkar bibit karet, perusahaan leasing kendaraan, dealer kendaraan bermotor serta perusahaan leasing dan toko elektronik dan furniture di sekitar wilayah sentra karet di Sumatera Selatan. Hasil penelitian menunjukkan bahwa turunnya harga karet saat ini telah memberikan dampak yang mengakibatkan turunnya pendapatan petani per bulan, turunnya kemampuan investasi petani, turunnya daya beli petani, serta pengalihan sumber penghasilan petani kepada sumber penghasilan selain usaha tani karet. Bahkan telah terjadi pengalihan fungsi lahan dari usaha tani karet ke tanaman lain yang dinilai petani lebih prospektif. Oleh karena itu diperlukan upaya-upaya agar bisa bertahan dalam kondisi harga karet yang rendah saat ini.

Kata kunci : Dampak; penurunan harga karet; sosial ekonomi; petani karet 


\section{PENDAHULUAN}

Saat ini ada 6 negara produsen utama karet alam dunia yaitu Thailand, Indonesia, Malaysia, India, Vietnam dan China. Indonesia masih menjadi penghasil karet alam kedua terbesar setelah Thailand. Total luas areal perkebunan karet di Indonesia hampir mencapai 3,5 juta $\mathrm{Ha}$ dengan produksi sebesar 3,3 juta ton. Luasan tersebut didominasi oleh perkebunan karet rakyat yang pada tahun 2012 telah meliputi areal seluas 3 juta hektar atau sekitar $81 \%$ dari total areal karet nasional, dengan produksi sekitar $80 \%$ dari total produksi karet alam nasional (Badan Pusat Statistik [BPS], 2013). Hampir seluruh petani karet di Indonesia adalah petani tradisional yang membangun kebun secara swadaya atau tanpa bantuan pemerintah.

Sejak tahun 2001 sampai tahun 2011 (kecuali pada saat krisis global tahun 2008/2009), harga karet alam meningkat sangat signifikan. Meningkatnya harga karet tersebut merupakan salah satu pemicu pesatnya penanaman karet yang dilakukan petani, hal ini terlihat dari pesatnya peningkatan produksi karet alam di Sumatera Selatan yang merupakan provinsi penghasil karet alam terbesar di Indonesia.

Pesatnya peningkatan produksi karet di Sumatera Selatan pada saat harga karet tinggi disebabkan oleh beberapa faktor diantaranya: 1) Pesatnya laju pembangunan kebun/peremajaan yang dilakukan petani secara swadaya. Setiap tahun terdapat 2530 petani yang melakukan peremajaan karet dengan total luasan rata-rata 47 Ha di setiap desa (Syarifa, Nancy, Agustina, \& Supriadi, 2012). Di Sumatera Selatan terdapat sekitar 2500 desa yang mata pencaharian utama penduduknya adalah bertani karet; 2) Meningkatnya adopsi bibit karet unggul. Pada tahun 1980 -an terdapat $40 \%$ petani yang menanam bahan tanam klon unggul (Hendratno \& Supriadi, 2011), sedangkan pada tahun 2010 jumlah petani yang mengadopsi klon unggul sudah mencapai 60-70\% (Syarifa et al., 2012); serta 3) Banyaknya pembangunan pabrik pengolahan karet yang dapat menampung karet yang dihasilkan petani. Hingga tahun 2012 jumlah pabrik pengolahan karet yang berdiri dan beroperasi di Sumatera Selatan mencapai sebanyak 27 pabrik (Gabungan Pengusaha Karet Indonesia [Gapkindo], 2014).

Dalam rentang waktu sejak tahun 2011 sampai pertengahan tahun 2014, telah terjadi perubahan yang sangat signifikan terhadap kondisi harga karet, yang mana harga karet alam yang sebelumnya mencapai sekitar USD 4,5 per kg SIR 20 di tahun 2011 terus menurun hingga mencapai hanya sekitar USD 1,6 per $\mathrm{kg}$ SIR 20 di pertengahan tahun 2014 (Gambar 1).

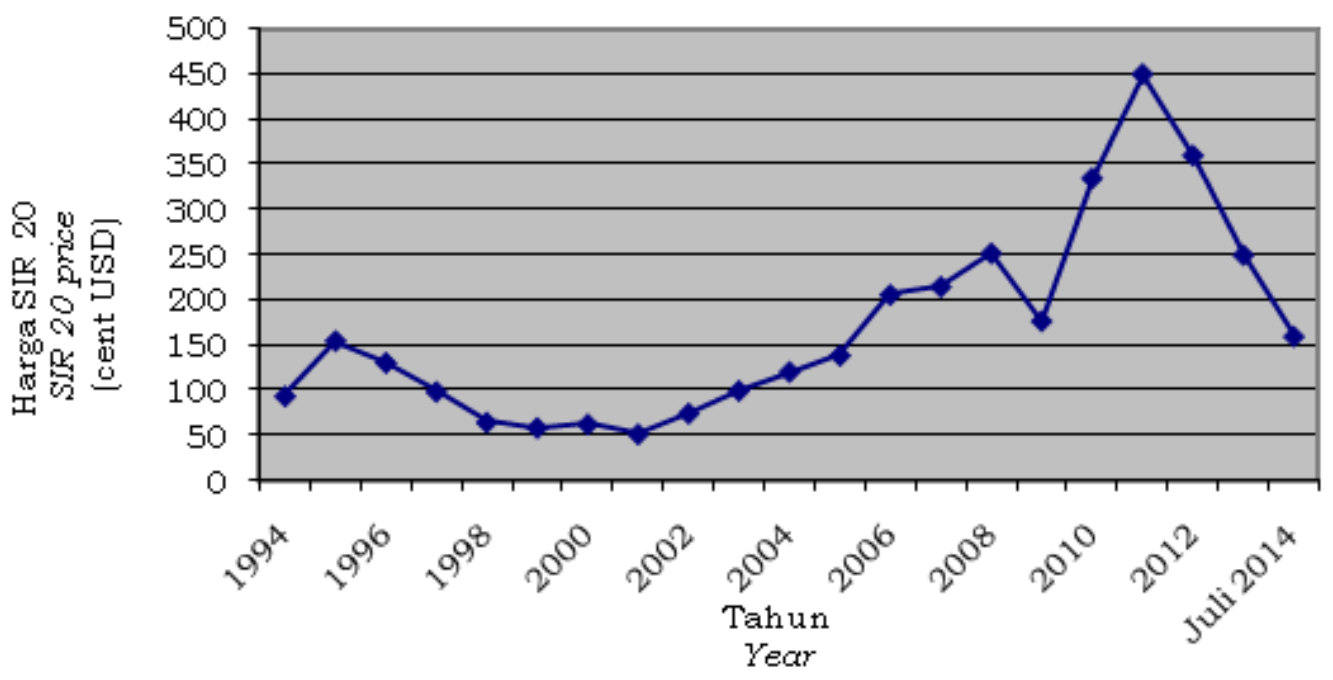

Gambar 1. Grafik fluktuasi harga karet, 1994-2014

Figure 1. The graph of rubber price fluctuation, 1994-2014

Sumber (Source): Singapore Commodity Exchange [SICOM], 2014 
Penurunan harga karet tersebut diduga telah memberikan berbagai dampak terhadap kondisi sosial ekonomi petani karet khususnya di Sumatera Selatan dikarenakan hampir 800 ribu KK atau 46\% penduduk Sum atera Selatan menggantungkan hidupnya dari komoditas karet (Direktorat Jenderal Perkebunan [Dirjenbun], 2013; BPS Sumsel, 2012). Tulisan ini akan menguraikan hasil penelitian mengenai dampak turunnya harga karet terhadap kondisi sosial ekonomi petani karet di Sumatera Selatan.

\section{BAHAN DAN METODE}

Kegiatan penelitian dilakukan di Provinsi Sumatera Selatan pada tahun 2014. Penelitian dilakukan dengan metode survei dengan mengambil sampel petani karet di beberapa wilayah sentra karet yang dipilih

Tabel 1. Jumlah responden

Table 1. The number of respondence

\begin{tabular}{|c|c|c|c|}
\hline $\begin{array}{l}\text { No. } \\
\text { No. }\end{array}$ & $\begin{array}{l}\text { Responden } \\
\text { Respondence }\end{array}$ & $\begin{array}{c}\text { Lokasi } \\
\text { (Kabupaten/Kota) } \\
\text { Location } \\
\text { (District/City) }\end{array}$ & $\begin{array}{c}\text { Total } \\
\text { (orang dan perusahaan) } \\
\text { Total } \\
\text { (peoples and companies) }\end{array}$ \\
\hline 1. & Petani karet & $\begin{array}{l}\text { Banyuasin, Kab. OKU } \\
\text { Induk, OKU Timur }\end{array}$ & 25 \\
\hline 2. & Penangkar bibit & Banyuasin & 10 \\
\hline 3. & $\begin{array}{l}\text { Perusahaan leasing } \\
\text { Kendaraan bermotor }\end{array}$ & $\begin{array}{l}\text { Banyuasin, dan } \\
\text { Palembang (Kantor Pusat) }\end{array}$ & 2 \\
\hline 4. & $\begin{array}{l}\text { Perusahaan leasing dan toko } \\
\text { elektronik dan furnitur }\end{array}$ & Banyuasin & 1 \\
\hline 5. & Dealer kendaraan & $\begin{array}{l}\text { Banyuasin, dan } \\
\text { Palembang (Main Dealer) }\end{array}$ & 2 \\
\hline
\end{tabular}

Data yang diambil meliputi data primer dan data sekunder. Data primer diperoleh melalui wawancara dengan menggunakan kuesioner dan diskusi dengan sampel terpilih. Sedangkan data sekunder diperoleh melalui literatur. Data yang diperoleh diolah dan dianalisis secara deskriptif, dengan membandingkan kondisi pada saat harga karet tinggi pada tahun 2011 dengan kondisi pada saat harga karet rendah pada tahun 2014.

\section{HASIL DAN PEMBAHASAN}

Rendahnya harga karet telah berdampak terhadap pendapatan petani secara acak. Dampak sosial ekonomi di tingkat petani akibat turunnya harga karet diduga juga berpengaruh terhadap daya beli petani dalam pembelian bibit karet, dan barang-barang sekunder lainnya. Sehingga, pengamatan juga dilakukan terhadap sampel petani penangkar bibit, perusahaan leasing kendaraan, dealer kendaraan bermotor serta perusahaan leasing dan toko elektronik dan furniture di sekitar wilayah sentra karet di Sumatera Selatan yang dipilih secara sengaja. Kabupaten Banyuasin merupakan salah satu sentra pembibitan terbesar di Sumatera Selatan. Oleh karena itu sampel penangkar bibit karet dipilih dari sentra pembibitan di Banyuasin. Perusahaan leasing dan dealer utama kendaraan bermotor yang terpilih memiliki data penjualan kendaraan dari seluruh kabupaten sentra karet di Sumatera Selatan (Tabel 1).

\begin{abstract}
karet per bulan, kemampuan investasi petani, daya beli petani terhadap barangbarang primer dan sekunder, serta pengalihan sumber penghasilan petani kepada sumber penghasilan selain usaha tani karet. Bahkan disinyalir telah terjadi pengalihan fungsi lahan dari peruntukan usaha tani karet ke tanaman lain yang lebih prospektif.
\end{abstract}

\section{Dampak Rendahnya Harga Karet Terhadap Pendapatan Petani}

Hasil penelitian menunjukkan bahwa pada tahun 2014 saat harga karet rendah menjadi USD 1,6 per kg, terjadi penurunan pendapatan petani yang cukup 
signifikan apabila dibandingkan dengan pendapatan petani di tahun 2011. Pada tahun 2011, saat harga karet mencapai sekitar USD 4,5 per kg, pendapatan petani pada tahun sadap pertama mencapai IDR 1,94 juta per bulan bila disadap sendiri. Apabila jumlah ini dibandingkan dengan tingkat Upah Minimum Regional (UMR) Sumsel pada tahun 2011 yang sebesar IDR 1,26 juta per bulan, maka pendapatan petani masih di atas UMR Sumsel. Selanjutnya, pendapatan petani di tahun sadap kedua sudah mencapai sekitar IDR 2,6 juta per bulan bila disadap sendiri, dan mencapai sekitar IDR 1,29 juta per bulan bila disadap dengan sistem bagi hasil, yang artinya pada saat ini pendapatan petani karet baik yang menyadap sendiri maupun yang menyadap dengan sistem bagi hasil sudah berada di atas UMR Sumsel. Dapat disimpulkan bahwa umumnya petani karet di Sumsel dinilai sejahtera pada saat harga karet mencapai USD 4,5 per kg.

Pada tahun 2014, saat harga karet SIR 20 turun menjadi sekitar USD 1,6 per kg, harga bokar yang diterima di tingkat petani hanya berkisar sebesar IDR 7.000,-/ kg slab mingguan (Kadar Karet Kering [KKK] 50\%). Apabila keluarga petani hanya memiliki kebun karet klonal seluas $1 \mathrm{Ha}$, maka pendapatan yang diperoleh pada tahun sadap pertama sekitar IDR 0,84 juta per bulan bila disadap sendiri, atau memperoleh sekitar IDR 0,42 juta per bulan bila disadap dengan sistem bagi hasil. Jumlah pendapatan tersebut masih sangat rendah dibandingkan dengan nilai UMR Sumsel tahun 2014 yang sebesar IDR 2 juta/bulan (Tabel 2). Pada kondisi harga karet saat ini, agar pendapatan dari usaha tani karet bisa setara dengan UMR,maka keluarga petani

Tabel 2. Perhitungan pendapatan usaha tani karet (klonal) per hektar

Table 2. Calculation of rubber clonal income per hectar

\begin{tabular}{|c|c|c|c|c|c|c|c|}
\hline \multirow{2}{*}{$\begin{array}{l}\text { Tahun } \\
\text { sadap } \\
\text { Year of }\end{array}$} & \multicolumn{7}{|c|}{$\begin{array}{l}\text { Produksi dan pendapatan usahatani karet klonal per Ha } \\
\text { Production and rubber clonal income per } \mathrm{Ha}\end{array}$} \\
\hline & \multirow{3}{*}{$\begin{array}{c}\text { Produksi / hari } \\
\text { Production / } \\
\text { day } \\
\text { (Kg slab) }\end{array}$} & \multirow{3}{*}{$\begin{array}{c}\text { Jumlah hari sadap } \\
\text { (hari per minggu) } \\
\text { Tapping day } \\
\text { (day/ week) }\end{array}$} & \multirow{3}{*}{$\begin{array}{l}\text { Produksi / minggu } \\
\text { Production/ week } \\
\text { (Kg slab) }\end{array}$} & \multicolumn{2}{|c|}{$\begin{array}{l}\text { Pendapatan sadap sendiri } \\
\quad(\mathrm{Rp} / \mathrm{Ha}) \text { per bulan }{ }^{\mathrm{a}}\end{array}$} & \multicolumn{2}{|c|}{$\begin{array}{l}\text { Pendapatan bagi hasil } \\
\text { (Rp/Ha) per bulan }{ }^{\text {d) }}\end{array}$} \\
\hline & & & & Tahun & Tahun & Tahun & Tahun \\
\hline & & & & $2011^{b)}$ & 2014c) & 2011 & 2014 \\
\hline 1 & 15 & 2 & 30 & 1944000 & 844800 & 972000 & 422400 \\
\hline 2 & 20 & 2 & 40 & 2592000 & 1126400 & 1296000 & 563200 \\
\hline 3 & 25 & 3 & 75 & 4860000 & 2112000 & 2430000 & 1056000 \\
\hline 4 & 30 & 3 & 90 & 5832000 & 2534400 & 2916000 & 1267200 \\
\hline
\end{tabular}

harus memiliki kebun karet klonal minimal seluas 2 Ha yang disadap sendiri, atau minimal memiliki 4 Ha kebun karet klonal yang disadap dengan sistem bagi hasil. Namun apabila keluarga tani menggarap kebun karet seedling yang produktivitasnya lebih rendah dari karet klonal, maka petani harus memiliki kebun karet yang lebih luas untuk memperoleh pendapatan yang setara dengan UMR.

Asumsi-asumsi:

a) Upah Minimum Regional (UMR) Sumsel tahun 2011 sekitar IDR 1,26 juta/bulan (IDR 50 ribu/hari); dan UMR tahun 2014 sekitar IDR 2 juta/bulan (IDR 77 ribu/hari)

b) Tahun 2011, harga karet SIR 20: USD 4,5/kg, Kurs: IDR 9.000/USD, harga per kg karet kering di tingkat petani $80 \%$ FOB SIR 20, dan KKK slab basah mingguan di tingkat petani sebesar $50 \%$.

c) Tahun 2014, harga karet SIR 20: USD $1,6 / \mathrm{kg}$, Kurs: IDR $11.000 /$ USD, harga per kg karet kering di tingkat petani $80 \%$ FOB SIR 20, dan KKK slab basah mingguan di tingkat petani sebesar 50\%. 
d) Sistem bagi hasil: maro, yaitu 50\% penyadap dan $50 \%$ pemilik

\section{Dampak Rendahnya Harga Karet Terhadap Daya Beli Petani}

Pada saat harga karet tinggi, terjadi peningkatan pendapatan dan kesejahteraan rumah tangga petani. Peningkatan pendapatan petani menyebabkan terjadinya peningkatan konsumsi untuk barang dan jasa (Hendratno, Nancy, Syarifa, \& Agustina, 2006 ). Petani mampu untuk mengalokasikan pendapatannya untuk membeli barang-barang kebutuhan sekunder antara lain kendaraan bermotor, barang-barang elektronik, barang-barang furnitur dan barang sekunder lainnya. Namun kondisi yang sebaliknya terjadi pada saat harga karet rendah. Turunnya pendapatan petani penggarap, terutama bagi buruh sadap, berakibat pada turunnya daya beli petani terhadap barang-barang primer maupun sekunder. Hal ini sangat mempengaruhi kondisi perekonomian secara umum di Sumatera Selatan, dikarenakan komoditi karet alam melibatkan lebih dari $40 \%$ penduduknya. Akibat dari daya beli yang merosot, perputaran roda perekonomian di daerah menjadi melemah. Pasar tradisional dan modern baik di daerah maupun di kota terlihat relatif lebih sepi.

Turunnya daya beli petani dapat terlihat dari turunnya omzet penjualan kendaraan bermotor serta barang kebutuhan sekunder lainnya. Data penelitian menunjukkan, pada tahun 2014 omzet penjualan kendaraan bermotor turun menjadi $50 \%$ dibandingkan pada saat harga karet tinggi di tahun 2011. Hal yang sama juga terjadi pada omzet penjualan barangbarang sekunder lainnya seperti elektronik dan furnitur yang menurun hingga mencapai 50\% dibandingkan tahun 2011. Selanjutnya, di perusahaan leasing kendaraan maupun barang elektronik dan furnitur, terjadi kenaikan kredit macet (Gambar 2). Bahkan pada saat ini, karena tidak mampu membayar angsuran, banyak petani yang mengembalikan motor atau barang-barang elektronik ke perusahaan leasing.

\section{Dampak Rendahnya Harga Karet Terhadap Kemampuan Petani Untuk Berinvestasi}

Peningkatan pendapatan petani karena kenaikan harga karet telah menyebabkan terjadinya peningkatan investasi yang dilakukan petani untuk membangun kebun karet dengan menggunakan klon unggul (Hendratno et al., 2006). Pada saat harga karet tinggi, banyak petani yang memperluas kebun karetnya dengan menggunakan bibit unggul. Sebaliknya pada saat harga karet menurun, kemampuan petani untuk membangun kebun karet juga menurun. Turunnya kemampuan petani dalam membangun kebun karet dapat dilihat dari menurunnya penjualan bibit karet unggul di tingkat penangkar bibit. Data penelitian menunjukkan, tingginya minat petani dalam membangun kebun karet mulai terjadi pada saat harga karet meningkat yaitu mulai tahun tanam 2010/2011, yang mana pada waktu itu permintaan bibit karet dari petani cukup tinggi. Selanjutnya permintaan bibit semakin meningkat pada tahun tanam 2011/2012. Pada kondisi ini, petani memiliki modal yang cukup untuk membangun kebun dan memiliki harapan bahwa di masa mendatang harga karet akan terus meningkat. Namun pada saat harga mulai menurun di tahun tanam 2012/2013, permintaan bibit juga terus menurun hingga tahun tanam 2013/2014 menjadi hanya sekitar $51 \%$ dibanding tahun tanam 2010/2011 (Gambar 3).

Menurunnya harga karet saat ini diharapkan dapat menjadi momentum bagi program peremajaan karet. Tujuan peremajaan menurut Iskandar (1984) adalah untuk mencapai efisiensi sebesar mungkin sehingga memperoleh keuntungan yang makin besar. Keuntungan untuk melakukan peremajaan pada saat harga karet turun adalah berupa kesempatan untuk menggunakan bahan tanam baru berupa klon unggul hasil pemuliaan dan seleksi terakhir. Alternatif pilihan pekebun karet untuk memutuskan peremajaan atau penundaan adalah jika perkiraan pendapatan yang diperoleh dari peremajaan lebih besar dibandingkan dengan pendapatan dari penyadapan yang sedang dilakukan maka akan melakukan peremajaan. Jika pendapatan dari penyadapan lebih besar dibandingkan 

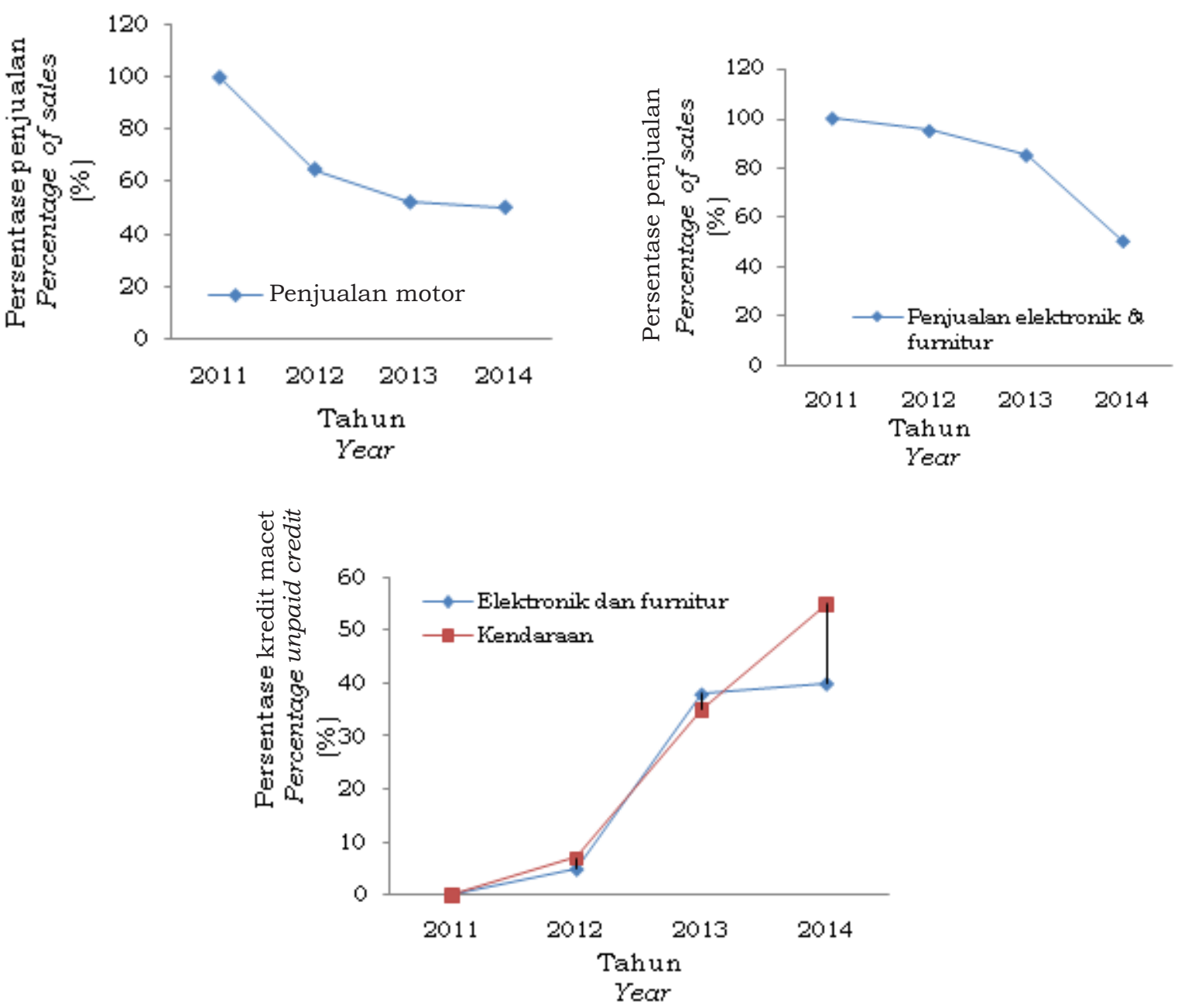

Gambar 2. Indikator turunnya daya beli petani karet terhadap barang-barang sekunder Figure 2. Indicators of decreasing of farmer's purchasing power to secondary goods Sumber (Source): Data primer (diolah)

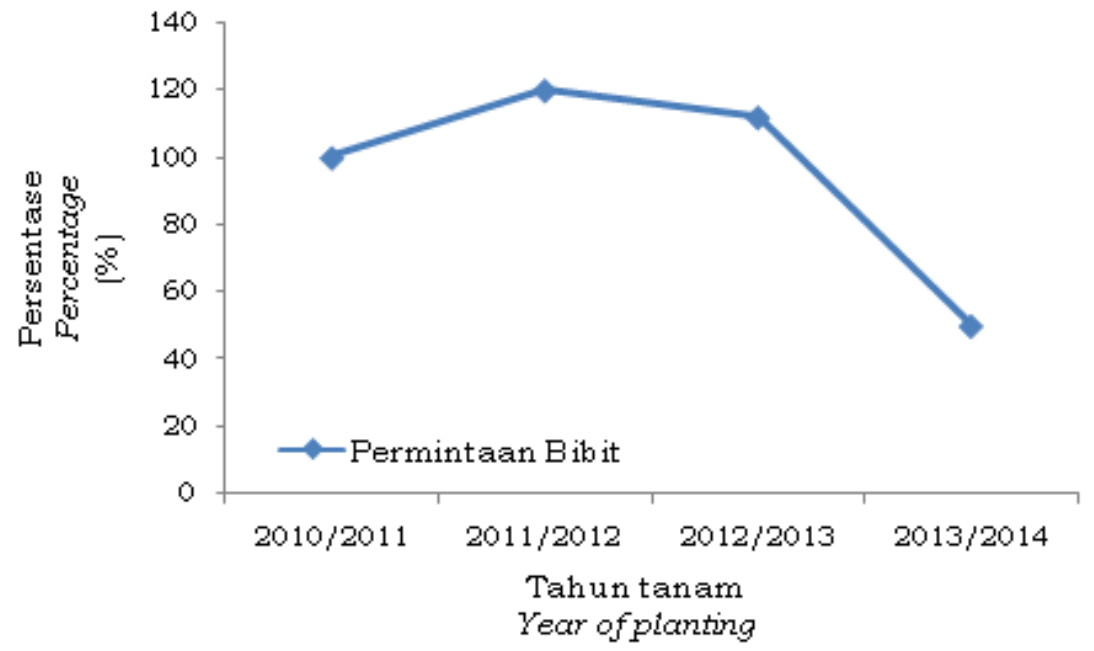

Gambar 3. Turunnya permintaan bibit karet Figure 3. The decrease of rubber planting material demand Sumber (Source): Data primer (diolah) 
dengan melakukan peremajaan maka akan melakukan penundaan peremajaan (Jayasuriya \& Carrad, 1977).

\section{Dampak Rendahnya Harga Karet Terhadap Perubahan Sumber Penghasilan Keluarga Petani}

Pada saat harga karet tinggi semua kebutuhan hidup rumah tangga petani dapat dipenuhi dari usaha tani karet. Oleh karena itu, keluarga petani lebih banyak mengalokasikan tenaga kerja keluarga produktif untuk usahatani karet (Hendratno et al., 2006). Pada saat harga karet rendah, penghasilan dari usaha tani karet tidak mampu mencukupi kebutuhan rumah tangga petani. Meskipun demikian, hasil pengamatan menunjukkan bahwa sebagian petani masih tetap menyadap karet dalam kondisi harga dan produksi karet yang turun saat ini. Namun untuk mencukupi kebutuhan rumah tangga, sebagian dari anggota keluarga petani ataupun buruh sadap terpaksa mencari penghasilan tambahan dengan bekerja sampingan di luar usaha tani karet seperti: menjadi buruh perkebunan sawit, perkebunan tebu maupun bekerja di proyek infrastruktur seperti pengaspalan jalan, penggalian pipa, dan lain sebagainya. Hasil studi juga menunjukkan belum terdapat adanya konversi lahan perkebunan karet rakyat secara besar-besaran menjadi lahan perkebunan sawit atau komoditi perkebunan lainnya. Hal ini dikarenakan sebagian besar petani karet telah terbiasa mengelola kebun karet secara turun temurun, sehingga mereka belum banyak yang mengerti untuk mengelola tanaman lain. Oleh karena itu, sebagian besar petani karet belum banyak berminat untuk mengganti tanaman karet dengan tanaman lainnya.

Namun apabila kondisi harga karet yang rendah saat ini berlangsung lama, dikhawatirkan secara berangsur-angsur akan mulai terjadi pengalihan fungsi lahan perkebunan karet menjadi perkebunan komoditi lain yang lebih prospektif. Dari hasil survei yang dilakukan di Kabupaten Ogan Komering Ulu Timur diketahui saat ini, sebagian kecil petani karet di Kabupaten Ogan Komering Ulu Timur mulai mengganti tanaman karet tua menjadi tanaman ubi kayu yang menjadi sumber penghasilan utama. Sedangkan tanaman karet yang masih muda dan produktif tetap disadap sebagai sumber penghasilan tambahan. Tanaman ubi kayu dinilai bisa memberikan kontribusi pendapatan yang lebih menjanjikan dibandingkan dengan tanaman karet pada kondisi harga karet saat ini. Apabila dibandingkan dengan tanaman

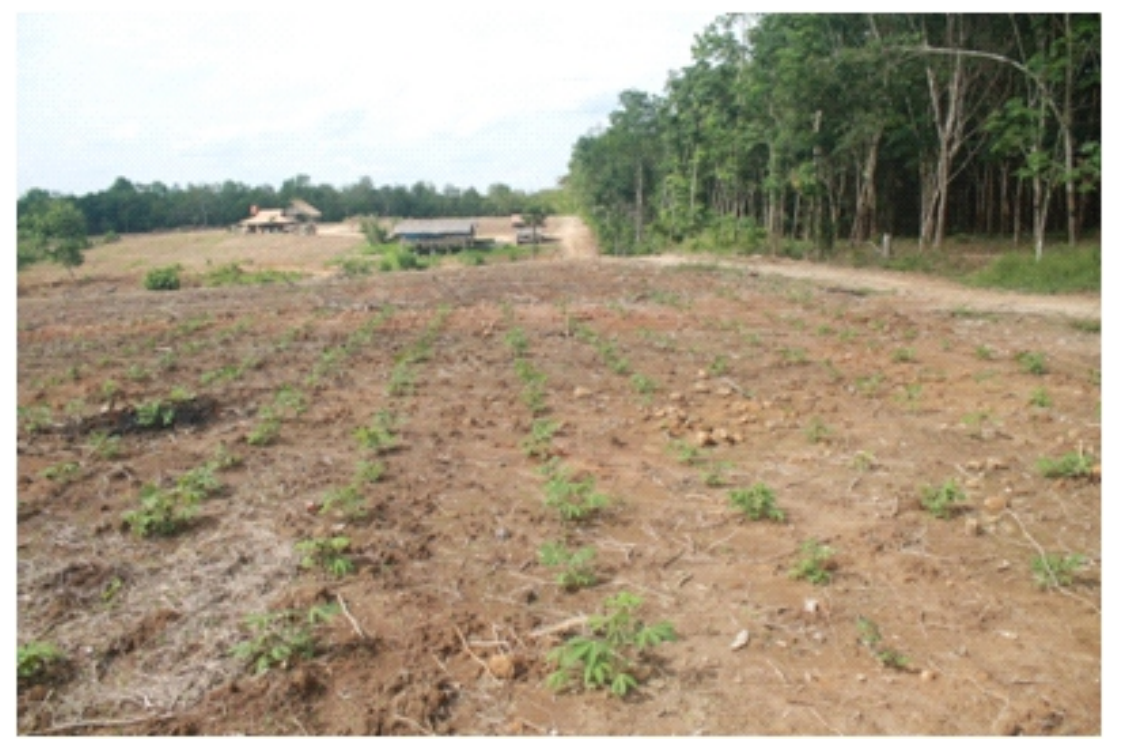

Gambar 4.Tanaman karet tua yang diganti dengan tanaman ubi kayu di Kabupaten Ogan Komering Ulu Timur

Figure 4. Old rubber trees replaced by cassava in East Ogan Komering Ulu District

Sumber (Source): Data primer (diolah) 
karet, 1 Ha tanaman ubi kayu dapat memberikan pendapatan rata-rata sebesar IDR 3,5 juta per bulan, sedangkan tanaman karet hanya memberikan pendapatan ratarata sebesar IDR 1,2 juta per bulan. Pada saat ini, di desa Tanjung Kukuh, Kabupaten Ogan Komering Ulu Timur seluas $\pm 800 \mathrm{Ha}$ tanaman karet tua telah diganti dengan tanaman ubi kayu (Gambar 4). Apabila belum ada kenaikan harga karet dalam setahun ke depan, diperkirakan akan semakin banyak tanaman karet tua di Kabupaten Ogan Komering Ulu Timur yang diganti menjadi tanaman ubi kayu.

\section{KESIMPULAN}

Rendahnya harga karet saat ini telah memberikan dampak yang pendapatan petani per bulan, turunnya kemampuan investasi petani untuk membagun kebun karet unggul, turunnya daya beli petani terhadap barang-barang primer dan sekunder, serta pengalihan sumber penghasilan petani kepada sumber penghasilan selain usahatani karet. Bahkan telah terjadi pengalihan fungsi lahan dari peruntukan usahatani karet ke tanaman lain yang lebih prospektif. Petani karet hanya bisa bertindak sebagai penerima harga dan tidak mampu untuk mempengaruhi perubahan harga karet. Oleh karena itu, diperlukan upaya-upaya agar bisa bertahan dalam kondisi harga karet yang rendah saat ini melalui peningkatan produktivitas kebun, yaitu menanam bibit unggul yang berproduktivitas tinggi dan melakukan penyadapan sesuai anjuran, disamping mengusahakan tanaman sela sebagai tambahan pendapatan; serta upaya peningkatan harga karet yang diterima di tingkat petani melalui peningkatan mutu bokar yang dihasilkan dan efisiensi pemasaran. Selain itu upaya lain yang dapat dilakukan untuk meningkatkan harga karet adalah dengan pembuatan inovasi yang dapat mendorong peningkatan konsumsi karet alam di dalam negeri, misalnya pembangunan infrastruktur dengan menggunakan karet alam

\section{DAFTAR PUSTAKA}

Badan Pusat Statistik. (2013). Statistik karet Indonesia 2013. Jakarta, Indonesia: BPS.

Badan Pusat Statistik Provinsi Sumatera Selatan. (2012). Penduduk. Diakses dari http://sumsel.bps.go.id /site/content/id.

Direktorat Jenderal Perkebunan. (2013). Statistik Perkebunan Indonesia. Karet 2011-2012. Jakarta, Indonesia: Dirjebun.

Gabungan Perusahaan Karet Indonesia. (2014). Bulletin Karet.Jakarta, Indonesia: Gapkindo.

Hendratno, S., Nancy, C., Syarifa, L. F.,\& Agustina, D. S. (2006). Dampak peningkatan harga karet terhadap kesejahteraan dan alokasi sumber daya rumah tangga petani (Kasus di wilayah eks PIRTRANS Batumarta, Sumatera Selatan). Prosiding Lokakarya dan Budidaya Tanaman Karet 2006 (pp. 326-341). Medan, Indonesia: Pusat Penelitian Karet.

Hendratno, S., \& Supriadi, M.(2011). Peningkatan produktivitas kebun melalui peremajaan dan penanaman klon karet unggul. Prosiding Lokakarya Karet Nasional 2011. Jakarta, Indonesia: Pusat Penelitian Karet.

Iskandar. (1984). Pengantar Budidaya Karet. Bogor, Indonesia: Institut Pertanian Bogor

Jayasuriya, S. K. W., \& Carrad, B. (1977). Decision making in smallholding rubber : attitutes to replanting in Sri Lanka. Journal Rubber Research Institute of Sri Lanka, 54(1), 381-397.

Singapore Commodity Exchange Limited. (2014). Market Information [Grafik]. Diakses dari www.sgx.com

Syarifa, L. F., Agustina, D. S., Nancy, C., \& Supriadi, M. (2012). Evaluasi tingkat adopsi klon unggul di tingkat petani karet propinsi Sumatera Selatan. Jurnal Penelitian Karet, 30(1), 12-22. 